University of Nebraska - Lincoln

DigitalCommons@University of Nebraska - Lincoln

2-1-2001

\title{
Use of flow cytometry, fluorescence microscopy, and PCR-based techniques to assess intraspecific and interspecific matings of Armillaria species
}

\author{
Mee-Sook Kim \\ University of Nebraska-Lincoln \\ Ned B. Klopfenstein \\ USDA Forest Service, RMRS, Forestry Sciences Lab, Moscow, ID, nklopfenstein@fs.fed.us \\ Geral I. McDonald \\ USDA Forest Service, RMRS, Forestry Sciences Lab, 1221 South Main, Moscow, ID \\ Kathiravetpillai Arumuganathan \\ University of Nebraska-Lincoln \\ Anne K. Vidaver \\ University of Nebraska-Lincoln, avidaver1@unl.edu
}

Follow this and additional works at: https://digitalcommons.unl.edu/plantpathpapers

Part of the Plant Pathology Commons

Kim, Mee-Sook; Klopfenstein, Ned B.; McDonald, Geral I.; Arumuganathan, Kathiravetpillai; and Vidaver, Anne K., "Use of flow cytometry, fluorescence microscopy, and PCR-based techniques to assess intraspecific and interspecific matings of Armillaria species" (2001). Papers in Plant Pathology. 98.

https://digitalcommons.unl.edu/plantpathpapers/98

This Article is brought to you for free and open access by the Plant Pathology Department at DigitalCommons@University of Nebraska - Lincoln. It has been accepted for inclusion in Papers in Plant Pathology by an authorized administrator of DigitalCommons@University of Nebraska - Lincoln. 


\title{
Use of flow cytometry, fluorescence microscopy, and PCR- based techniques to assess intraspecific and interspecific matings of Armillaria species
}

\author{
Mee-Sook KIM ${ }^{1 *}$, Ned B. KLOPFENSTEIN ${ }^{2}$, Geral I. McDONALD ${ }^{2}$, Kathiravetpillai ARUMUGANATHAN ${ }^{3}$ \\ and Anne K. VIDAVER ${ }^{1}$ \\ ${ }^{1}$ Department of Plant Pathology, University of Nebraska, Lincoln, NE 68583-0722, USA. \\ ${ }^{2}$ USDA Forest Service, RMRS, Forestry Sciences Lab, 1221 South Main, Moscow, ID 83843-4298, USA. \\ ${ }^{3}$ Center for Biotechnology, University of Nebraska, Lincoln, NE 68588-0665, USA. \\ E-mail:meeskim@uidaho.edu \\ Received 18 November 1999; accepted 3 May 2000.
}

For assessments of intraspecific mating using flow cytometry and fluorescence microscopy, two compatible basidiospore-derived isolates were selected from each of four parental basidiomata of North American Biological Species (NABS) X. The nuclear status in NABS X varied with basidiospore-derived isolates. Nuclei within basidiospore-derived isolates existed as haploids, diploids (doubled haploids), or a mixture of haploids and diploids (doubled haploids). Depending on the nuclear status of the basidiospore-derived lines of NABS X, intraspecifically mated cultures can exist as diploids or tetraploids, and possibly triploids or aneuploids under in vitro conditions. Based on previous in vitro mating studies, seven basidiospore isolates were specifically selected to assess rare, interspecific mating among Armillaria cepistipes, A. sinapina, NABS X, and NABS XI. Cultures from basidiospore-derived isolates were paired to produce four interspecifically paired cultures, and matings were assessed using flow cytometry and restriction fragment length polymorphism (RFLP) analyses. Based on flow cytometric analysis, the A. cepistipes isolate exhibited compatibility with a NABS X isolate, and the A. sinapina isolate exhibited compatibility with a NABS X isolate, and the $A$. sinapina isolates were individually compatible with isolates of NABS X and NABS XI. Mean fluorescence intensities of A. cepistipes $\times$ NABS X, A. sinapina $\times$ NABS X, and $A$. sinapina $\times$ NABS XI mated cultures revealed a triploid or tetraploid nuclear status compared to the haploid or diploid (doubled haploid) nuclear status of initial basidiospore-derived isolates. Polymerase chain reaction (PCR) and RFLP of the intergenic spacer (IGS) region generated banding patterns for basidiospore-derived isolates and mated cultures. Four species-specific RFLP banding patterns were observed in basidiospore-derived isolates of A. cepistipes, A. sinapina, NABS X, and NABS XI. PCR-RFLP analysis showed combined banding patterns from mated cultures. Flow cytometry and PCR-RFLP analysis are effective tools to assess matings of Armillaria species.

\section{INTRODUCTION}

The vegetative phase of most basidiomycetes exists as a dikaryon, where two haploid nuclei are paired in each cell, and the dikaryon state is maintained in new growth by clamp connections. However, clamp connections and dikaryotic cells occur only briefly in the life-cycle of many Armillaria species (Korhonen \& Hintikka 1974, Larsen et al. 1992, Tommerup \& Broadbent 1975) and the persistent stage is usually diploid (Franklin et al. 1983, Korhonen 1980, Ullrich \& Anderson 1978). Microspectrophotometry was previously used to examine stages in the nuclear cycle of $A$. mellea, basidiospores were found to be haploid, monosporous isolates were generally diploid, and trama tissues were perhaps diploid (Peabody et al. 1978). In subsequent studies on A. mellea, Franklin, Filion \&

* Present address: Department of Forest Resources, University of Idaho, Moscow, ID 83844, USA. This manuscript has been assigned Journal Series No. 12780, Agricultural Research Division, University of Nebraska.
Anderson (1983) demonstrated that basidiospore-derived mycelia were haploid and mated cultures were diploid.

Studies on sexual compatibility among Armillaria species frequently indicate low-level compatibility among isolates ascribed to separate species. Examples of low-level compatibility included paired A. sinapina-A. cepistipes $(5.5 \%$ compatible), A. sinapina-NABS X (3.5\% compatible), $A$. sinapina-NABS XI (5\% compatible), A. cepistipes-NABS X (6.5\% compatible), NABS X-NABS XI (4\% compatible) (Banik \& Burdsall, 1998). Bérubé et al. (1996) examined the compatibility between $A$. sinapina and $A$. cepistipes and reported these species were $2.1 \%$ to $6.7 \%$ compatible. Anderson, Korhonen \& Ullrich (1980) and McDonald et al. (1998) also reported that $A$. cepistipes has shown compatibility with NABS X isolates. Although such low-level compatibility does not necessarily indicate conspecificity, it does indicate a potential mechanism for gene flow among Armillaria species or populations.

Confirming compatibility among Armillaria isolates is a 
complex process. Macroscopic assessments of compatibility by characteristic culture reactions are occasionally unreliable (Banik \& Burdsall 1998, McDonald, unpubl.). Compatibility assessments can be improved by examining morphological traits (e.g. clamp connections or swollen cells) of paired mycelia at the microscopic level (Larsen et al. 1992); however, false negative and false positive reactions still occur (McDonald \& Larsen, unpubl.). If unique genetic markers are apparent in individual isolates, molecular genetic techniques can be used to demonstrate the presence of combined markers in mated cultures of compatible isolates.

Anderson \& Stasovski (1992) used the polymerase chain reaction (PCR) to amplify the Intergenic Spacer (IGS) of the ribosomal RNA operon, and sequenced this region for several Armillaria species to determine phylogenetic relationships. Based on the IGS sequences, Harrington \& Wingfield (1995) developed a simplified PCR-based method in which the IGS region is amplified, then cut with restriction endonucleases to produce restriction fragment length polymorphisms (RFLPs) that are species-specific. Mating among Armillaria species is evident if the mated culture contains IGS RFLPs from both basidiospore-derived lines of the mated culture. However, PCR-RFLP techniques cannot distinguish between nuclear combination and intermingled mycelia of separate genetic backgrounds. Protoplast and hyphal tip cultures can help establish uniformity of mated cultures; however, these techniques are laborious and may not reflect the overall condition of the mated culture. Because vegetative or mated mycelia of Armillaria species typically exist in the diploid state (Franklin et al. 1983, Korhonen 1980, Ullrich \& Anderson 1978), determination of diploidization or nuclear combination can help verify mating among intraspecific and interspecific crosses. Flow cytometry offers the potential to assess the nuclear status resulting from intraspecific and interspecific matings of Armillaria.

Measurement of DNA content (Ormerod 1990) is one of the most widespread applications of flow cytometry. Such measurements can assist studies of ploidy levels through the fungal life cycle. Several researchers found that the vegetative stage of Armillaria species exists in the diploid state (Franklin et al. 1983, Korhonen 1980, Ullrich \& Anderson 1978). In our previous work, flow cytometry was used to quantify nuclear DNA contents of 70 isolates of North American Armillaria species that originated from vegetative tissues (i.e. mycelial fan, rhizomorph, stipe, or context tissue) and matings of basidiospore-derived cultures. Based on these measurements, diploid nuclear DNA contents of Armillaria species varied with species: A. ostoyae (0.117 pg per $2 \mathrm{C}), A$. sinapina (0.152 pg per $2 \mathrm{C})$, NABS X (0.155 pg per $2 \mathrm{C})$, NABS XI (0.152 pg per 2C), and A. gallica (0.173 pg per 2C) (Kim et al. 2000). If flow cytometry shows uniform diploidization (or nuclear combination) in a mated culture of two basidiosporederived mycelia, such evidence would support that a mating has occurred and that the mated mycelia are of uniform nuclear status. Flow cytometry can be used to assess nuclear status and ploidy level of basidiospore-derived isolates and their mated cultures, and fluorescence microscopy can be used to determine whether mycelial cells are monokaryotic, dikaryotic, or polykaryotic.
This study used flow cytometry and fluorescence microscopy to assess the nuclear status of intraspecific mating with NABSX and interspecific matings among selected Armillaria species. PCR-RFLPs also were used to verify nuclear combinations in rare interspecific matings of Armillaria species. The objectives of this study were to: (1) assess the nuclear status and ploidy level of selected basidiosporederived isolates, intraspecifically mated cultures, and interspecifically mated cultures using flow cytometry and fluorescence microscopy; (2) verify whether differences exist in the nuclear DNA contents of basidiospore-derived isolates and their mated cultures using flow cytometry; and (3) determine the status of nuclear combination from interspecific mating using IGS RFLP analysis.

\section{MATERIALS AND METHODS}

\section{Fungal isolates for intraspecific and interspecific mating studies}

In previous studies with NABS $X$, individual basidiosporederived cultures were established in addition to cultures of parental basidioma tissue (McDonald, unpubl.). All basidiospore-derived cultures were thoroughly characterized for mating alleles using the occurrence of clamp connections and culture reactions on oak wood extract-orange juice medium (Darmono \& Burdsall 1992, McDonald, unpubl.). For intraspecific mating studies, two compatible basidiospore-derived cultures were selected from each of four parental basidiomata (Table 1). Matings were accomplished by closely aligning subcultures of compatible basidiospore-derived isolates (Anderson \& Ullrich 1979, 1982, Darmono \& Burdsall 1992, Korhonen 1978, 1980, Larsen et al. 1992, Ullrich \& Anderson 1978), and allowing 6 weeks for completion of mating

Table 1. Armillaria NABS X isolates used for the intraspecific mating study ${ }^{\mathrm{a}}$.

\begin{tabular}{ll}
\hline Isolate no. & Source of isolate \\
\hline C7-3 $\left(\mathrm{A}_{1} \mathrm{~B}_{1}\right)^{\mathrm{b}}$ & basidiospore \\
C7-11 $\left(\mathrm{A}_{2} \mathrm{~B}_{2}\right)$ & basidiospore \\
C7-3 $\times$ C7-11 $\left(\mathrm{A}_{1} \mathrm{~B}_{1} \times \mathrm{A}_{2} \mathrm{~B}_{2}\right)$ & mated culture \\
C7-CAP & basidioma \\
D83-5 $\left(\mathrm{A}_{1} \mathrm{~B}_{1}\right)$ & basidiospore \\
D83-6 $\left(\mathrm{A}_{2} \mathrm{~B}_{2}\right)$ & basidiospore \\
D83-5 $\times$ D83-6 $\left(\mathrm{A}_{1} \mathrm{~B}_{1} \times \mathrm{A}_{2} \mathrm{~B}_{2}\right)$ & mated culture \\
D83-CAP & basidioma \\
$837-13\left(\mathrm{~A}_{1} \mathrm{~B}_{2}\right)$ & basidiospore \\
$837-25\left(\mathrm{~A}_{2} \mathrm{~B}_{1}\right)$ & basidiospore \\
$837-13 \times 837-25\left(\mathrm{~A}_{1} \mathrm{~B}_{2} \times \mathrm{A}_{2} \mathrm{~B}_{1}\right)$ & mated culture \\
$837-C A P$ & basidioma \\
C14-8 $\left(\mathrm{A}_{1} \mathrm{~B}_{2}\right)$ & basidiospore \\
C14-12 $\left(\mathrm{A}_{2} \mathrm{~B}_{1}\right)$ & basidiospore \\
C14-8 $\times$ C14-12 $\left(\mathrm{A}_{1} \mathrm{~B}_{2} \times \mathrm{A}_{2} \mathrm{~B}_{1}\right)$ & mated culture \\
C14-CAP & basidioma \\
\hline
\end{tabular}

${ }^{a}$ NABS $=$ North American Biological Species. All NABS X isolates represent separate genets (vegetative clones) originating from ID, USA.

${ }^{b}$ Mating alleles were identified previously, and $A B$ allele designations pertain only to each individual cap (McDonald, unpubl.).

c Two compatible basidiospore-derived isolates were selected from each of four basidiomata. 
Table 2. Armillaria isolates for the interspecific mating study.

\begin{tabular}{|c|c|c|c|c|}
\hline $\begin{array}{l}\text { Armillaria } \\
\text { species }\end{array}$ & Isolate & $\begin{array}{l}\text { Source of } \\
\text { isolates }\end{array}$ & Origin & Identifier \\
\hline A. cepistipes & $304-1$ & basidiospore & Finland & K. Korhonen \\
\hline A. sinapina & HB9 & basidiospore & WA, USA & H. Burdsall \\
\hline A. sinapina & ON18 & basidiospore & WA, USA & H. Burdsall \\
\hline $\mathrm{NABS}^{\mathrm{a}} \mathrm{X}$ & C $32-4$ & basidiospore & ID, USA & G. McDonald \\
\hline NABS $X$ & D83-6 & basidiospore & ID, USA & G. McDonald \\
\hline NABS $X$ & D84-11 & basidiospore & ID, USA & G. McDonald \\
\hline NABS XI & W112-4 & basidiospore & WA, USA & H. Burdsall \\
\hline $\mathrm{X}$-A. сер & C $32-4 \times 304-1$ & mated culture & & \\
\hline $\mathrm{XI}-A \cdot \sin$ & W112-4 $\times$ ON18 & mated culture & & \\
\hline $\mathrm{X}-A \cdot \sin$ & D83-6 × HB9 & mated culture & & \\
\hline $\mathrm{X}-A \cdot \sin$ & D84-11 $\times$ HB9 & mated culture & & \\
\hline
\end{tabular}

a $\mathrm{NABS}=$ North American Biological Species.

Table 3. Nuclear DNA content of NABS X determined by flow cytometry $^{\mathrm{a}}$

\begin{tabular}{ll}
\hline Armillaria NABS X isolates & $\begin{array}{l}\text { Nuclear DNA content } \\
\text { (pg per nucleus) }\end{array}$ \\
\hline C7-3 & $0.086 \pm 0.004^{\mathrm{c}}$ \\
& $0.159 \pm 0.008$ \\
C7-11 & $0.086 \pm 0.002$ \\
C7-3 $\times$ C7-11 & $0.156 \pm 0.003$ \\
C7-CAP & $0.156 \pm 0.013$ \\
D83-5 & $0.158 \pm 0.006$ \\
& $0.078 \pm 0.007$ \\
D83-6 & $0.141 \pm 0.011$ \\
D83-5 $\times$ D83-6 & $0.083 \pm 0.007$ \\
D83-CAP & $0.155 \pm 0.009$ \\
$837-13$ & $0.149 \pm 0.014$ \\
$837-25$ & $0.155 \pm 0.003$ \\
$837-13 \times 837-25$ & $0.155 \pm 0.003$ \\
$837-C A P$ & $0.270 \pm 0.022$ \\
C14-8 & $0.157 \pm 0.005$ \\
C14-12 & $0.152 \pm 0.006$ \\
C14-8 $\times$ C14-12 & $0.156 \pm 0.006$ \\
C14-CAP & $0.263 \pm 0.031$ \\
\hline
\end{tabular}

a $\mathrm{NABS}=$ North American Biological Species.

b The standard used for comparison was Chicken Red Blood Cells (2.33 pg/2C), for which the DNA content is known.

c Each number represents the mean \pm standard deviation of the mean of five replications. Each replication of Armillaria isolate DNA content was based on 10,000 scanned nuclei.

processes before subsequent subculture. Based on a previous interspecific pairing study (McDonald, unpubl.), seven isolates of A. cepistipes, A. sinapina, NABS X, and NABS XI were specifically selected for strong potential of interspecific matings based on multiple criteria including culture morphology and the occurrence of clamp connections (Table 2). These isolates were derived from basidiospores, and were previously identified by various investigators using pairing tests (Table 2). Interspecific matings were conducted following previously described methods (Anderson \& Ullrich 1979, 1982, Darmono \& Burdsall 1992, Korhonen 1978, 1980, Larsen et al. 1992, Ullrich \& Anderson 1978). For use in flow cytometry, fluorescence microscopy, and RFLP analysis, all isolates were maintained in Petri dishes on $3 \%$ malt agar medium (3\% malt extract, $1 \%$ peptone, $3 \%$ glucose, $1.5 \%$ agar) and incubated at $22{ }^{\circ} \mathrm{C}$ in the dark.

Cultures and long-term archives of the Armillaria species used in this study are maintained in the USDA Forest Service, RMRS, Forestry Sciences Laboratory (Moscow, ID). Cultures are publicly accessible and will be shipped world-wide, provided that the requestor has appropriate regulatory permits. Representative cultures are also being sent to the American Type Culture Collection (ATCC). Original basidiomes were not preserved.

\section{Flow cytometry and fluorescence microscopic analysis}

Flow cytometric techniques were used to assess the nuclear status of basidiospore-derived, basidioma-derived, and mated cultures. After incubating for 6 weeks at $22^{\circ}$, each mated culture was subcultured by excising a portion of dark- or brown-colored, crustose mycelia with a sterile scalpel blade, then placing it on fresh $3 \%$ malt agar medium. Following a 5week period, mycelia (ca. $30 \mathrm{mg}$ ) of each isolate were dissected away from the medium, and fixed in $4 \%(\mathrm{w} / \mathrm{v})$ formaldehyde in Tris buffer (10 mM Tris, $10 \mathrm{mM} \mathrm{Na-EDTA,} 100 \mathrm{mM} \mathrm{NaCl}$, $0.1 \%$ Triton-100, pH 7.4) (Bianciotto et al. 1995) for $15 \mathrm{~min}$, and then washed twice in Tris buffer. Intact nuclei were isolated in Tris buffer by repeatedly chopping the mycelia with a sharp scalpel blade. Suspended nuclei were filtered through nylon filters with a $30-\mu \mathrm{m}$ pore diameter. To a $0.7 \mathrm{ml}$ nuclear suspension, $2.5 \mu \mathrm{RNAse}\left(500 \mathrm{\mu g} \mathrm{m}^{-1}\right)$ were added, followed by gentle mixing with $20 \mu \mathrm{l}\left(5 \mathrm{mg} \mathrm{ml}^{-1}\right)$ of propidium iodide. All nuclear isolation procedures were conducted on ice, and resulting suspensions were incubated in the dark for $20 \mathrm{~min}$ at room temperature. Fluorescence of the propidium iodide stained nuclei was analyzed at the University of Nebraska-Center for Biotechnology Flow Cytometry Core Research Facilities using a FACScan Flow Cytometer (Becton Dickinson, San Jose, CA). Data were registered on logarithmic scales. Debris was excluded from the analysis by raising the FL3 threshold, and the appropriate threshold value was determined experimentally. For each sample and the internal standard, the mean positions of nuclear peaks were determined by analysis using CellQuest software (Becton Dickinson, San Jose, CA). Each measurement of fungal DNA content was 

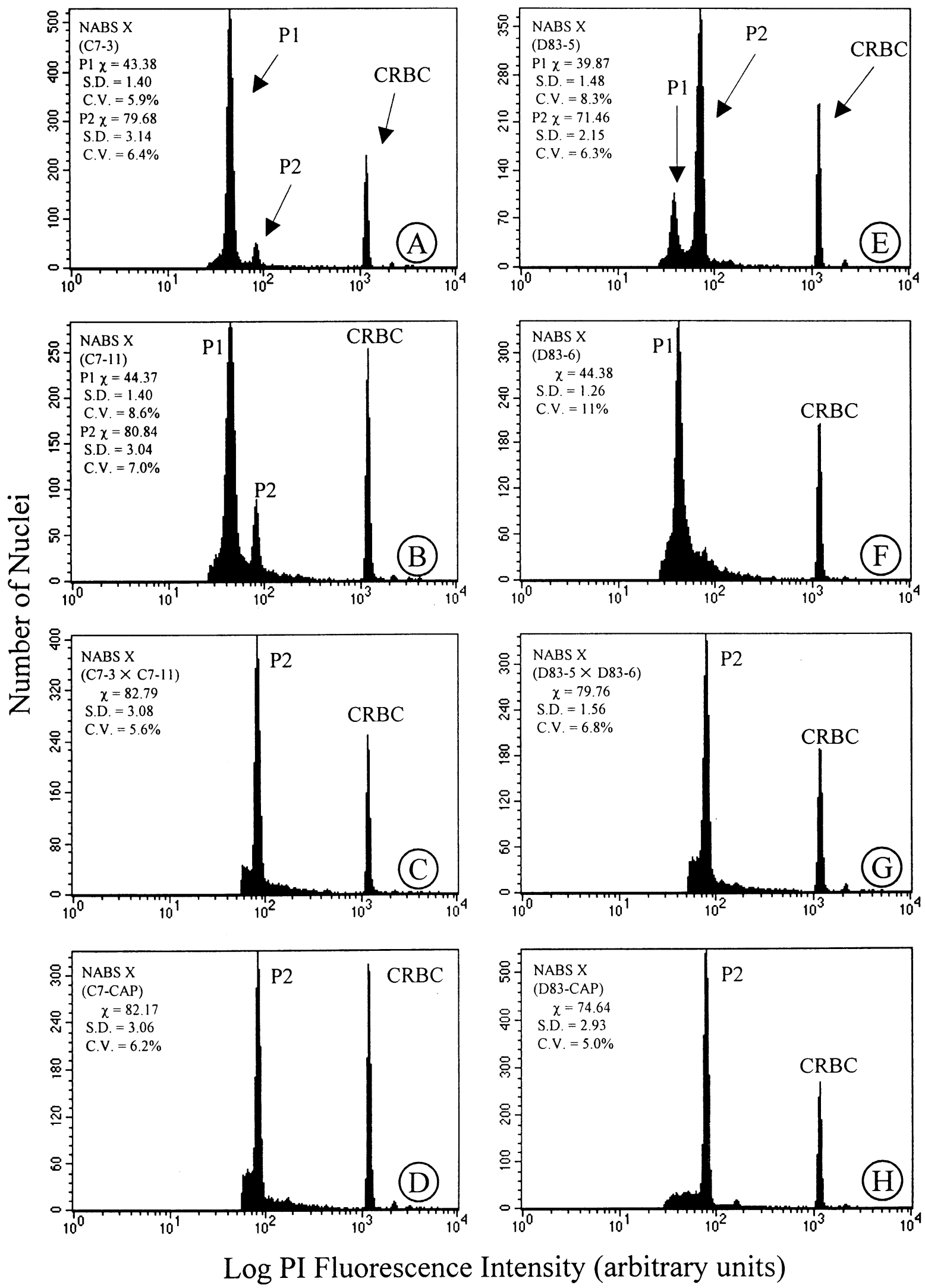

Fig. 1A-H. For legend see facing page.

based on 10,000 scanned nuclei. The standard used for comparison was chicken red blood cells (CRBC), for which the DNA content is known (2.33 pg/2C) (Galbraith et al. 1983). The formula used for converting fluorescence intensity values to DNA content was: Nuclear DNA content $=$ (mean fluorescence intensity of sample peak)/(mean fluorescence intensity of the standard peak) $\times$ DNA content of the standard $(2.33 \mathrm{pg})$. Flow cytometric analyses were conducted four or five times for each basidiospore-derived or basidioma-derived isolate and five or eight times for each mated culture. 

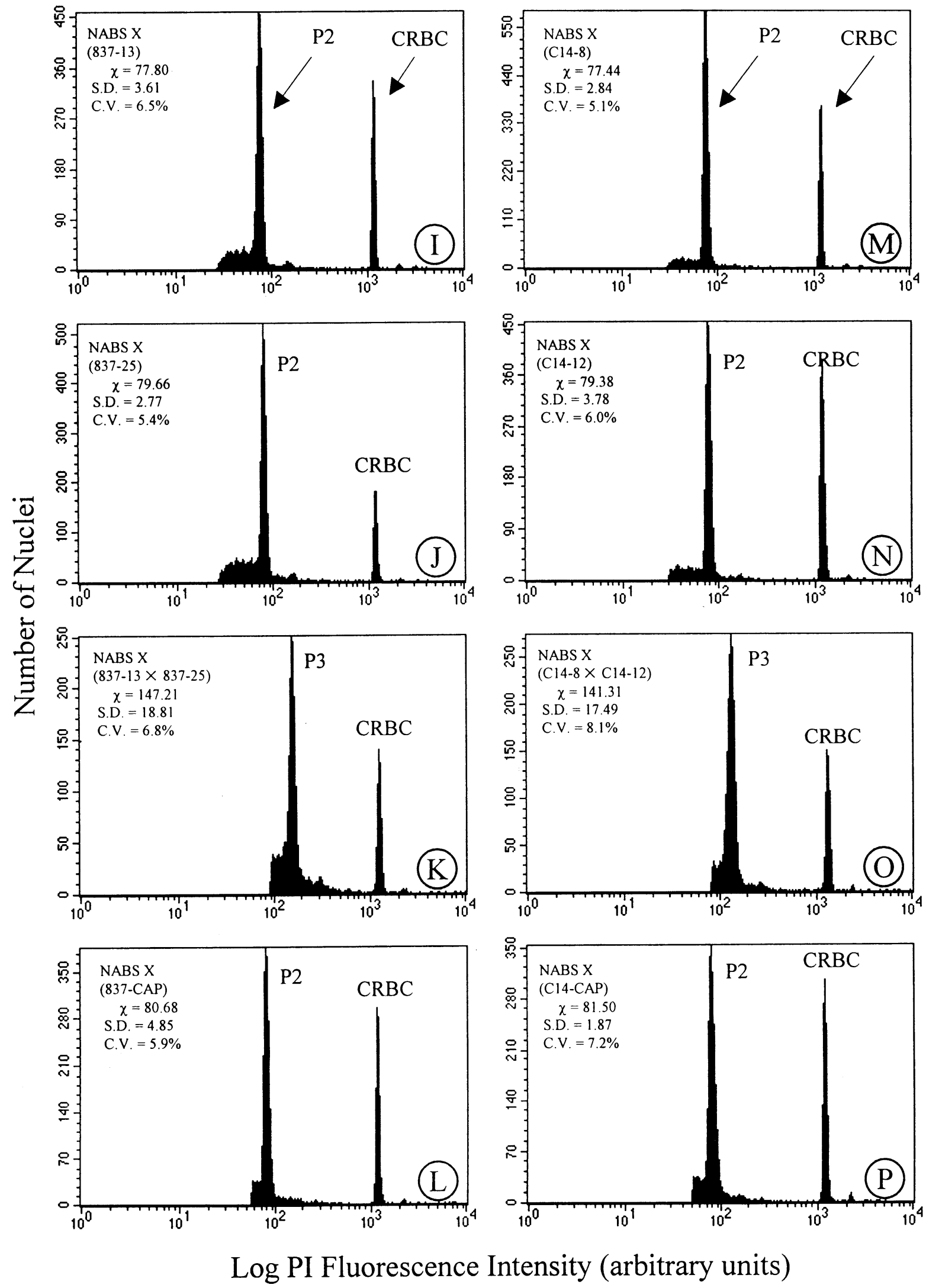

Fig. 1. Histograms showing numbers of given fluorescence intensities obtained by flow cytometry for propidium iodide-stained nuclei of Armillaria North American Biological Species X and chicken red blood cells (CRBC; 2.33 pg/nucleus). Isolates of Armillaria are described in Table 1. The mean of log fluorescence intensities (X), standard deviation (s.D.), and coefficient of variation (c.V.) are listed for the peak from each isolates. 
Fluorescent stained nuclei were observed with fluorescence microscopy to determine the number of nuclei per cell. Actively growing mycelia were dissected away from the $3 \%$ malt agar medium with a scalpel, then fixed in FAA $(4 \%$ formaldehyde, $2.5 \%$ acetic acid, and $47.5 \%$ ethanol in $0.1 \mathrm{M}$ phosphate buffer, $\mathrm{pH} 7.0$ ) for $6 \mathrm{~h}$ at $4^{\circ}$, then rinsed four times in 0.1 $\mathrm{M}$ phosphate buffer. Fixed nuclei were stained and mounted in Vectashield ${ }^{\circledR}$ mounting medium with $1.5 \mathrm{\mu g} \mathrm{ml}^{-1}$ 4',6-diamidino-2 phenylindole (DAPI) (Vector Laboratories, Inc., Burlingame, CA). Specimens were observed using an oil immersion lens and UV excitation light on a fluorescence microscope (Olympus BX60).

\section{Polymerase chain reaction, restriction endonuclease digestions, and electrophoresis}

The IGS-I region between the $3^{\prime}$ end of the large subunit ribosomal RNA (rRNA) gene and the $5^{\prime}$ end of the 5S rRNA gene was amplified using PCR. Template DNA was derived from scrapings of actively growing mycelial cultures (3-4 weeks old). The following primers were used: LR12R, 5'CTGAACGCCTCTAAGTCAGAA-3' (Veldman et al. 1981) and O-1, 5'-AGTCCTATGGCCGTGGAT-3' (Duchesne \& Anderson 1990). Each 100- $\mu$ l reaction mixture contained template DNA from a mycelial scraping (or no DNA template for negative control), 2.5 units Taq polymerase (Perkin-Elmer, Branchberg, NJ), PCR reaction buffer (supplied with Taq enzyme), $4 \mathrm{mM} \mathrm{MgCl} 2,200 \mu \mathrm{M}$ dNTPs, and $0.5 \mu \mathrm{M}$ of each primer (LRI2R and O-1). After an initial denaturation step at $95^{\circ}$ for $90 \mathrm{~s}, \mathrm{PCR}$ was conducted using 35 cycles of $90^{\circ}$ for $30 \mathrm{~s}$ (denaturation), $60^{\circ}$ for $40 \mathrm{~s}$ (annealing), and $72^{\circ}$ for $2 \mathrm{~min}$ (extension) using a Perkin-Elmer (480) thermocycler (Harrington \& Wingfield 1995). A final extension step at $72^{\circ}$ for 10 min was conducted to ensure complete amplification into a double-stranded product.

Restriction digestions were conducted with aliquots (i.e., 10-15 $\mu \mathrm{l}$ ) from PCR amplification mixtures. Because the enzyme Alu I (New England BioLabs, Beverly, MA) typically produces the most polymorphisms useful for species identification, it was the primary restriction endonuclease used on all PCR products (Harrington \& Wingfield 1995). Digestions were conducted using 5-10 units of restriction endonucleases for $8-12 \mathrm{~h}$ at $37^{\circ}$.

Intact and restriction-digested PCR products were electrophoresed in $2.5 \%$ MetaPhor ${ }^{\circledR}$ agarose (FMC BioProducts, Rockland, ME) gels using 0.5X TBE (89 mM Tris, $89 \mathrm{mM}$ boric acid, and $2 \mathrm{mM}$ EDTA) buffer. Electrophoresis was conducted at a constant $100 \mathrm{~V}$ for $4 \mathrm{~h}$. Gels were stained with ethidium bromide $\left(0.5 \mathrm{\mu g} \mathrm{ml}^{-1}\right)$ and bands were visualized using UV light. Gel images were analyzed using SigmaGel ${ }^{[\mathrm{m}}$ gel analysis software (SPSS Science, Chicago, IL).

\section{RESULTS}

\section{Intraspecific matings of Armillaria NABS $X$ isolates}

Nuclear DNA contents were quantified as shown in Table 3. The coefficients of variation for measurements of fluorescence intensity of all NABS X isolates ranged from $5 \%$ to $11 \%$ with a mean of $6.7 \%$ (Fig. 1). Nuclear DNA contents varied from $0.078 \mathrm{pg}$ (D83-5) to $0.159 \mathrm{pg}$ (C7-3) per nucleus for basidiospore-derived isolates and from $0.155 \mathrm{pg}$ (D83$5 \times \mathrm{D} 83-6)$ to $0.270 \mathrm{pg}(837-13 \times 837-25)$ per nucleus for mated cultures (Table 3). Nuclear DNA contents of basidioma (CAP)-derived isolates were 0.149 pg (D83-CAP) to 0.159 pg (C14-CAP) per nucleus (Table 3). Basidiospore-derived isolates C7-3, C7-11, and D83-5 showed two mean positions of nuclear peaks; the first peak (PI) corresponded to the haploid genome size $(0.078 \mathrm{pg}-0.086 \mathrm{pg}$ per nucleus) and the other peak (P2) corresponded to a diploid (doubled haploid) nuclear DNA content (0.141 pg-0.159 pg per nucleus) (Fig. IA-B, E). Other basidiospore-derived isolates, 837-13, 837-25, C148 , and C14-12, showed only one mean position of the nuclear peak; this peak (P2) corresponded to the diploid (doubled haploid) nuclear condition (DNA contents: $0.152 \mathrm{pg}-$ $0.156 \mathrm{pg}$ per nucleus) (Fig. II-J, M, N). One basidiosporederived isolate, D83-6, exhibited a single mean position of the nuclear peak (P1), which corresponded to a haploid genome size (0.083 pg per nucleus) (Fig. IF).

In mated cultures, a single mean position of the nuclear peak was observed (Fig. IC, G, K, O). Nuclear peaks of C7$3 \times$ C7-11 and D83-5 $\times$ D83-6 corresponded to the diploid nuclear DNA contents: $0.156 \mathrm{pg}$ per nucleus for C7-3 $\times$ C711 and 0.155 pg per nucleus for D83-5 × D83-6 (Fig. 1C, G). Nuclear peaks of $837-13 \times 837-25$ and C14-8 $\times$ C14-12 indicated their nuclear DNA contents was tetraploid: $0.270 \mathrm{pg}$ per nucleus for $837-13 \times 837-25$ and 0.263 pg per nucleus for C14-8 $\times$ C14-12 (Fig. 1K, O). Nuclei of all basidioma-derived isolates (C7, D83, 837, and C14) were diploid (0.149 pg per nucleus) (Fig. 1D, H, L, P). After DAPI staining, fluorescence microscopic observations revealed that all basidiosporederived and mated cultures were monokaryotic.

\section{Interspecific matings among A. cepistipes, A. sinapina, $N A B S X$, and NABS XI}

Nuclear DNA contents of Armillaria isolates as determined by laser flow cytometry are shown in Table 4 . The coefficients of variation for measurements of fluorescence intensity of all isolates ranged from $6 \%$ to $10 \%$ with mean of $7.9 \%$ (Fig. 2). Nuclear DNA contents varied from $0.083 \mathrm{pg}$ (A. sinapina ON18) to $0.159 \mathrm{pg}$ (NABS XI W112-4) per nucleus for basidiospore-derived isolates and from $0.232 \mathrm{pg}$ (NABSXI W112-4 $\times A$. sinapina ON18) to 0.260 pg (NABS X D84$11 \times$ A. sinapina HB9) per nucleus for mated cultures (Table 4). Basidiospore-derived isolates C32-4, ON18, and W112-4 showed two mean positions of nuclear peaks; the first peak (PI) corresponded to the haploid genome size $(0.083 \mathrm{pg}-$ $0.087 \mathrm{pg}$ per nucleus) and the other peak ( $\mathrm{P} 2)$ corresponded to a diploid (doubled haploid) nuclear DNA content (0.149 pg0.159 pg per nucleus) (Fig. $2 \mathrm{~A}, \mathrm{D}-\mathrm{E})$. Isolates 304-1, HB9, and D84-11 showed only one mean position of the nuclear peak; this peak (P2) corresponded to the diploid (doubled haploid) nuclear condition (nuclear DNA contents: $0.142 \mathrm{pg}-0.151 \mathrm{pg}$ per nucleus) (Fig. 2 B, H, J). In addition, isolate D83-6 exhibited only one mean position of the nuclear peak (P1), which corresponded to a haploid genome size (0.089 pg per nucleus) (Fig. 2G). 
Table 4. Nuclear DNA content of Armillaria species determined by flow cytometry and Alu I digestion fragment sizes (bp) of the intergenic spacer (IGS1) region from seven single-spore derived Armillaria isolates and four interspecifically mated cultures.

\begin{tabular}{|c|c|c|c|}
\hline Armillaria species & $\begin{array}{l}\text { Isolates } \\
\text { no. }\end{array}$ & $\begin{array}{l}\text { DNA content }{ }^{\mathrm{a}} \\
\text { (pg per nucleus) }\end{array}$ & $\begin{array}{l}\text { Alu I fragment sizes }{ }^{\mathrm{b}}(\mathrm{bp}) \text { of } \\
\text { IGS-1 region }\end{array}$ \\
\hline A. cepistipes & $304-1$ & $0.147 \pm 0.004^{c}$ & $309,199,137,92$ \\
\hline A. sinapina & HB9 & $0.142 \pm 0.002$ & $401,241,186$ \\
\hline A. sinapina & ON18. & $\begin{array}{l}0.083 \pm 0.001 \\
0.149 \pm 0.002\end{array}$ & $401,241,186$ \\
\hline $\mathrm{NABS}^{\mathrm{d}} \mathrm{X}$ & C $32-4$ & $\begin{array}{l}0.084 \pm 0.001 \\
0.155 \pm 0.001\end{array}$ & $401,186,144$ \\
\hline NABS $X$ & D83-6 & $0.089 \pm 0.002$ & $401,186,144$ \\
\hline NABS $X$ & D84-11 & $0.151 \pm 0.003$ & $401,186,144$ \\
\hline NABS XI & W112-4 & $\begin{array}{l}0.087 \pm 0.001 \\
0.159 \pm 0.004\end{array}$ & $401,197,186$ \\
\hline NABS X-A. cepistipes & C $32-4 \times 304-1$ & $0.251 \pm 0.006$ & $403,307,199,185,144,137,92$ \\
\hline NABS XI- $A$. sinapina & W112-4 $\times$ ON18 & $0.232 \pm 0.011$ & $400,241,197,185$ \\
\hline NABS X-A. sinapina & D83-6 $\times$ HB9 & $0.239 \pm 0.005$ & $400,240,186,144$ \\
\hline NABS X-A. sinapina & D84-11 × HB9 & $0.260 \pm 0.021$ & $401,240,186,144$ \\
\hline
\end{tabular}

a The standard used for comparison was Chicken Red Blood Cells $(2.33 \mathrm{pg} / 2 \mathrm{C})$, for which the DNA content is known.

${ }^{\mathrm{b}}$ Fragment sizes were determined from DNA size standards $\left(20 \mathrm{bp}\right.$ or $50 \mathrm{bp}$ ) using SigmaGel ${ }^{\circledR}$ gel analysis software. Values represent the mean of three replications from three different gels. Standard deviation of fragment size estimation was ca. $\pm 3 \mathrm{bp}$.

${ }^{c}$ Each number represents the mean \pm standard deviation of the mean of four (single spore-derived isolates) and eight (mated pair) replications. Each replication of Armillaria isolate DNA content was based on 10,000 scanned nuclei.

${ }^{d}$ NABS $=$ North American Biological Species.

In mated cultures, a single mean position of the nuclear peak was found (Fig. 2C, F, I, K). Nuclear peaks of NABS $\mathrm{X} \times A$. sinapina $(\mathrm{D} 83-6 \times \mathrm{HB} 9)$ and $\mathrm{NABS} \mathrm{XI} \times A$. sinapina (W112-4 $\times$ ON18) corresponded to the triploid nuclear DNA contents: $0.239 \mathrm{pg}$ per nucleus for D83-6 $\times \mathrm{HB} 9$ and $0.232 \mathrm{pg}$ per nucleus for W112-4 $\times$ ON18 (Fig. 2F, I). In addition, nuclear peaks of NABS X $\times$ A. cepistipes $(\mathrm{C} 32-4 \times 304-1)$ and NABS X $\times$ A. sinapina $($ D84-11 $\times$ HB9) were indicative of a tetraploid (or possibly triploid or aneuploid) nuclear DNA contents: $0.251 \mathrm{pg}$ per nucleus for $\mathrm{C} 32-4 \times 304-1$ and $0.260 \mathrm{pg}$ per nucleus for D84-11 $\times \mathrm{HB9}$ (Fig. 2C, K). Observations of DAPI stained mycelia under the fluorescence microscope indicated a monokaryotic condition was present in cells from basidiospore-derived and interspecifically mated cultures.

The amplified DNA products corresponding to the intergenic spacer (IGS-1) region were ca. $920 \mathrm{bp}$ for all isolates. Sizes of Alu I digestion fragments from seven basidiospore-derived isolates and four interspecifically mated cultures are presented in Table 4, and fragment patterns of Alu I digestion are shown in Fig. 3. Four distinct RFLP banding patterns were observed in basidiospore-derived isolates of $A$. cepistipes, A. sinapina, NABS X, and NABS XI (Fig. 3 lanes 1, 3, $6,8)$. PCR-RFLP analyses showed mated cultures contained combined banding patterns that represented a combination of both basidiospore-derived lines (Fig. 3 lanes 2, 4, 5, 7).

\section{DISCUSSION}

Armillaria cultures are slow growing, and the only nuclei that are dividing are those at the hyphal tips. Thus, the majority of nuclei analyzed by flow cytometry were not undergoing replication, and the few nuclei that were dividing were doing so at a relatively slow rate. In our flow cytometry studies on Armillaria spp., the peaks were consistent and uniform. As expected, relatively few nuclei possessed DNA undergoing replication, and flow cytometric analyses showed that the proportion of nuclei in G2 was negligible. Thus, peaks representing fused nuclei are quite distinct from those observed in $S$ or post-S phase nuclei.

It appears that basidiospore-derived isolates can exist in cultures as haploid, diploid (doubled haploid), or a mixture of haploid and diploid (doubled haploid). Basidiospore-derived cultures that showed a diploid nuclear DNA content are considered to be doubled haploids because they behaved as typical haploids in all previous mating reactions designed to identify mating alleles (McDonald, unpubl.). In addition, diploid nuclear DNA contents of A. sinapina, NABS X, and NABS XI were measured as $0.152 \mathrm{pg}$ to $0.155 \mathrm{pg}$ based on our previous studies (Kim et al. 2000). From these measurements, we anticipate that haploid genome sizes of $A$. sinapina, NABS X, and NABS XI range from $0.076 \mathrm{pg}$ to $0.078 \mathrm{pg}$. Because basidiospores were unavailable for our flow cytometry studies, we cannot verify when basidiosporederived cultures attained a diploid (doubled haploid) status. Presently, it is unknown whether cultures existing as doubled haploids and mixed nuclear status were naturally derived or represent a response to extended growth in culture. Although haploid isolates have been cultured for 7-12 years except isolate 304-1 (32 years), these isolates continue to behave as typical haploids in mating reactions (McDonald, unpubl.). Cultures of mixed nuclear status appeared to possess only one nucleus per cell. This condition suggests that spontaneous chromosomal doubling may occur during haploid culture. In previous studies on relative DNA content of $A$. mellea, Franklin et al. (1983) reported that basidiospores and monosporous isolates were haploid and that strains derived from matings of isolates of single spores were diploid; however, the results of Peabody, Motta \& Therrien (1978) differed from Franklin et al. (1983). Using Feulgen staining and 

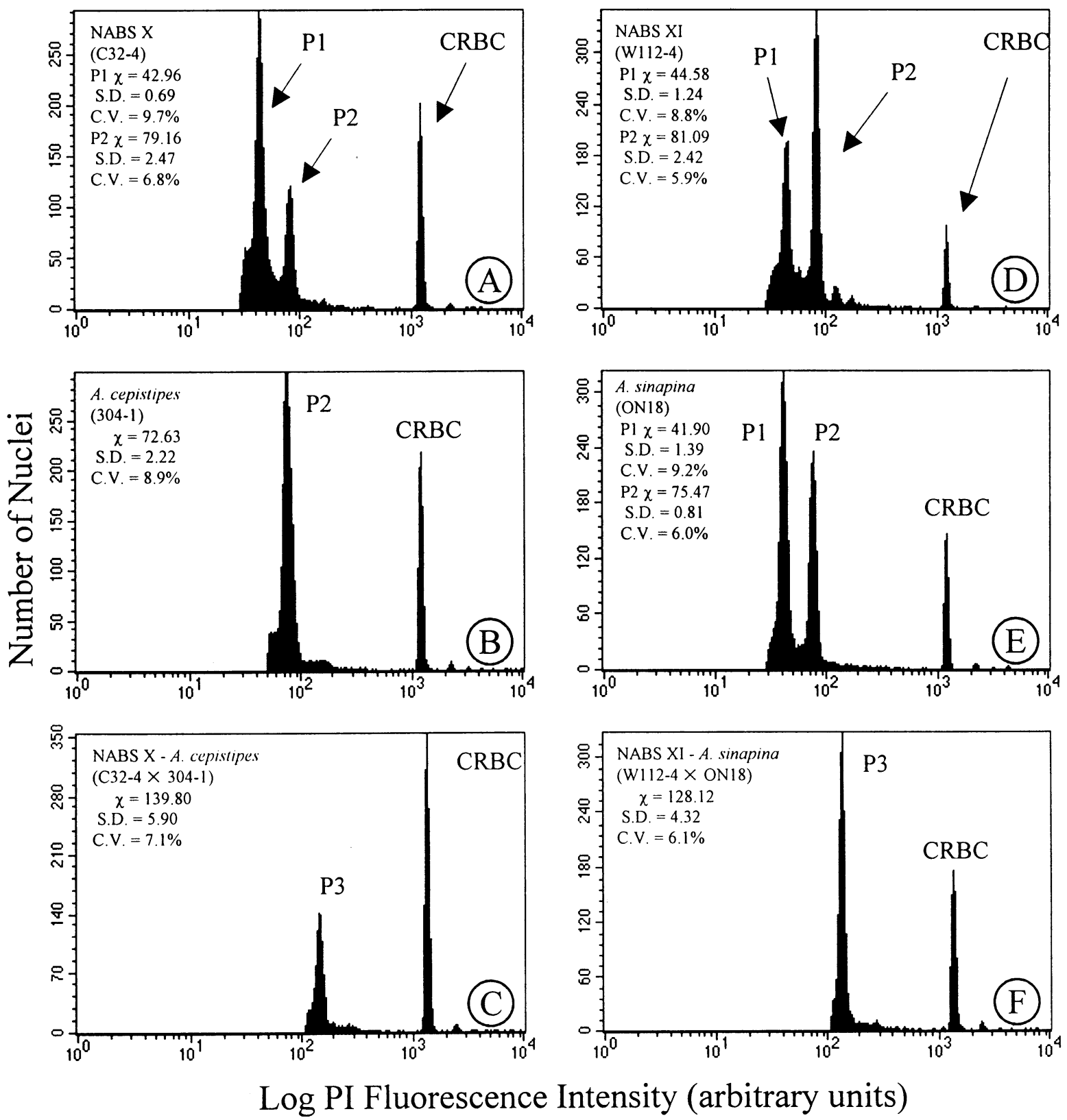

Fig. 2 A-F. For legend see facing page.

microspectrophotometry, Peabody et al. (1978) compared nuclear DNA content of several cell types in A. mellea. They concluded that basidiospores were haploid, but many monosporous isolates were diploid. Franklin et al. (1983) argued that diploid monosporous isolates would be difficult to reconcile based on observed mating behavior and bifactorial heterothallism. It appears that diploid monosporous isolates of Peabody et al. (1978) occurred by spontaneous chromosomal doubling. Such evidence further supports that the diploid nuclei in our basidiospore-derived cultures represent a doubled haploid state generated by spontaneous chromosomal doubling in culture.

Determination of diploidization or nuclear combination can help verify intraspecific and interspecific matings. Depending on the status of the basidiospore-derived lines, intra- and interspecific mating cultures can potentially exist as diploids, triploids, tetraploids, or aneuploids. Our results show that cultures from intraspecific and interspecific matings possessed nuclei with a homogeneous unimodal distribution, demonstrating a single ploidy level resulting from nuclear fusion or combination (Fig. 1C, G, K, O, Fig. 2C, F, I, K). The ecological role and biological significance of ploidy level in the natural life cycle and in vitro culture of Armillaria species is not yet determined. Continued studies are needed to determine the ploidy of naturally produced basidiospores, basidiomata, rhizomorphs, and mycelial fans. Further investigations are also required to determine the origin of triploidy or tetraploidy, exemplified by both intra- and interspecifically mated cultures. The mechanisms regulating nuclear combination also warrant further study. The natural occurrence of aneuploidy, triploidy, tetraploidy, or other ploidy level is not well understood for Armillaria species. In our previous work, diploidy was a common nuclear condition among culture isolates derived from vegetative mycelia (e.g. rhizomorphs or 

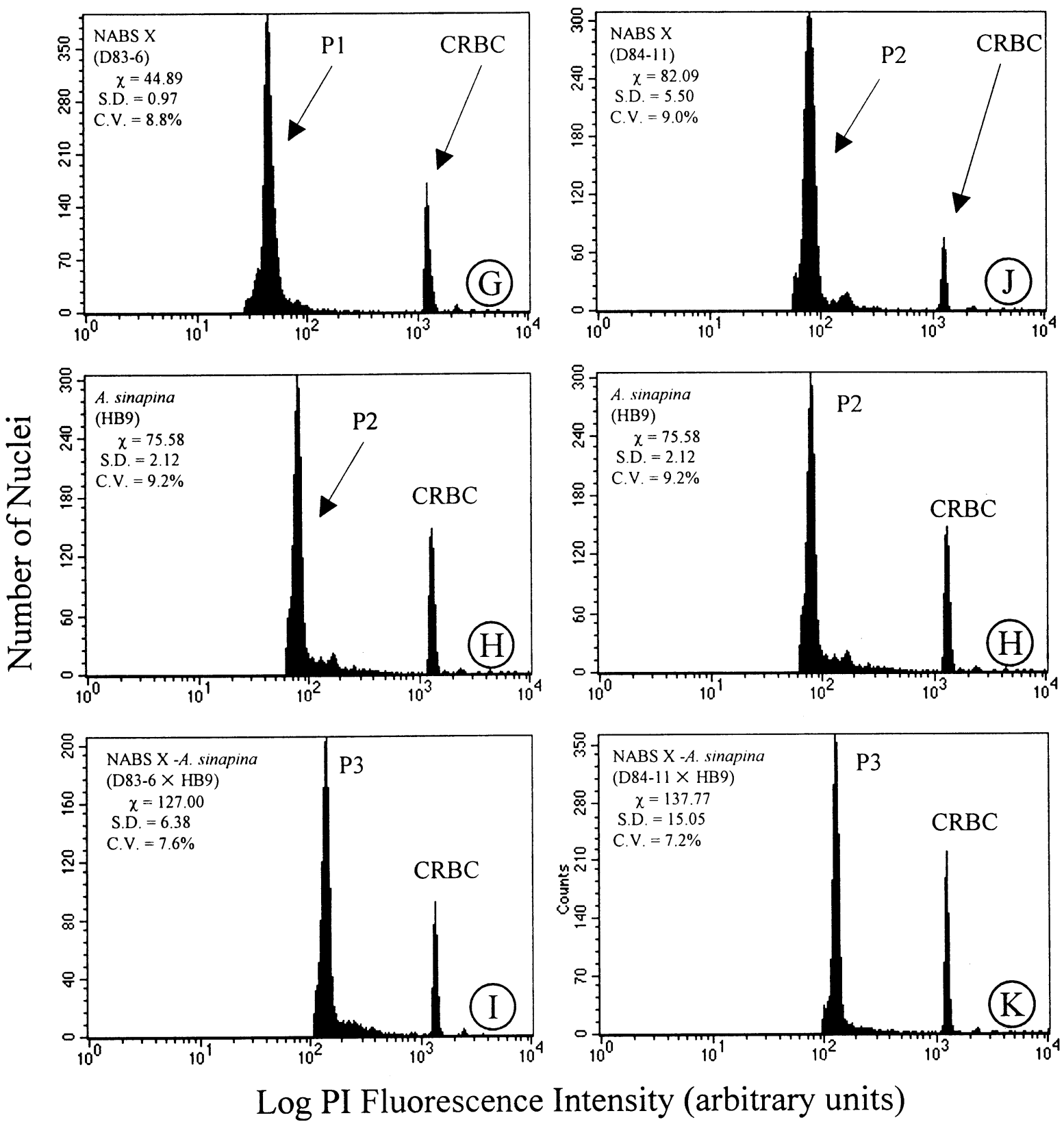

Fig. 2. Histograms showing numbers of given fluorescence intensities obtained by flow cytometry for propidium iodide-stained nuclei of Armillaria isolates and chicken red blood cells (CRBC; $2.33 \mathrm{pc} /$ nucleus). Isolates of Armillaria are described in Table 2. The mean of $\log$ fluorescence intensities (X), standard deviation (S.D.), and coefficient of variation (C.V.) are listed for the peak from each isolate.

mycelial fans) of North American Armillaria species (Kim et al., unpubl.). After examining 35 cultures isolated from vegetative mycelial samples in northern Idaho, only one isolate, $A$. ostoyae (isolated from a mycelial fan) was found to exist in the triploid nuclear state (Kim et al., unpubl.). Ploidy level could potentially influence mating, adaptation, compatibility, reproduction, pathogenicity, or other interactions with biotic and abiotic environments. Continued studies with flow cytometry, fluorescence microscopy, and genetic markers can help determine the role of ploidy level and nuclear combination in the ecology and in vitro studies of Armillaria species.

All of the RFLP banding patterns of $A$. cepistipes, A. sinapina, NABS X, and NABS XI observed for the IGS- $A$ lu I digestions correspond to those reported earlier (Banik \& Burdsall 1998,
Banik et al. 1996, Harrington \& Wingfield 1995, White et al. 1998). Nuclear combination of interspecific matings was verified by identification of RFLP combined patterns that were a combination of both basidiospore-derived lines (Fig. 3, lanes 2, 4, 5, 7). Banik \& Burdsall (1998) reported IGS RFLPs banding patterns are very useful genetic markers for assessing nuclear combination among Armillaria species. When morphological ratings (e.g. crustose) indicated successful mating among $A$. sinapina, A. cepistipes, NABS X, and NABS XI, these paired cultures generally showed combined IGS RFLPs banding patterns from both basidiospore-derived lines of the paired culture (Banik \& Burdsall 1998). Only one RFLP banding pattern of IGS-1 or ITS (internal transcribed spacer) regions was present in NABS X (Fig. 3 lane 3), and thus this 


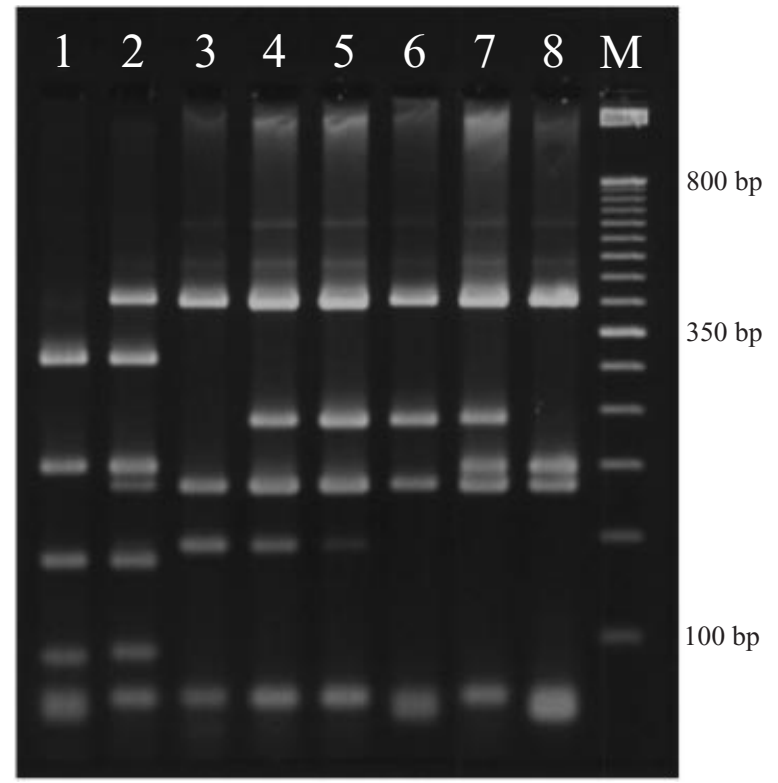

Fig. 3. PCR-RFLP band patterns of Armillaria species intergenic spacer (IGS-1) digested with Alu I. Lanes: $\mathrm{I}=$ A. cepistipes (304-1); 2 $=$ North American Biological Species $(\mathrm{NABS}) \mathrm{X} \times$ A. cepistipes $(\mathrm{C} 32-$ $4 \times 304-1) ; 3=$ NABS $X(32-4) ; 4=$ NABS $X \times A$. sinapina (D83$6 \times \mathrm{HB} 9) ; 5=\mathrm{NABS} \times \times$ A. sinapina $(\mathrm{D} 84-11 \times \mathrm{HB} 9) ; 6=A$. sina pina (HB9); $7=\mathrm{NABS} \mathrm{XI} \times A$. sinapina (W112-4 $\times$ ON18); $8=$ NABS XI (W112-4). Size markers (M; 50 bp) in base pairs are shown on far right.

RFLP analysis could not be used to assess nuclear combinations for the intraspecific matings.

In previous work, Anderson et al. (1980) also studied the monosporous isolate 304-1 (corresponds to isolate 2.3/1 in Anderson et al. 1980) which was used in our study of interspecific matings. In the previous work, isolate 304-1 appeared compatible in pairings with isolates of NABS $X$ (Anderson et al. 1980). These studies demonstrate conclusively that select basidiospore-derived isolates of NABS X can undergo genetic recombination with select basidiosporederived isolates of $A$. cepistipes or $A$. sinapina under laboratory conditions. Similarly, select basidiospore-derived isolates of NABS XI can genetically recombine in vitro with select basidiospore-derived isolates of $A$. sinapina. Macroscopic and microscopic observations of interspecific pairing indicate that interspecific mating occurs at relatively low frequency within the A. sinapina, NABS X, NABS XI, and A. cepistipes group. Continued use of flow cytometry with molecular genetic markers can address issues regarding phylogenetic and ecological significance of such matings. Further studies are also needed to more broadly characterize the genetic basis of interspecific matings and potential avenues of gene flow within the important genus Armillaria.

\section{ACKNOWLEDGEMENTS}

This paper was supported in part by the Biotechnology Graduate Research Associateship program of the Center for Biotechnology, Nebraska Statewide Arboretum Graduate Research Fellowship, the Department of Plant Pathology at the University of Nebraska-Lincoln, and the Storkan-Hanes Foundation. We thank Alan Harvey and Gary Yuen for their comments to an earlier version of this manuscript. We also thank Harold Burdsall for Armillaria isolates, and James Donley and Richard Carman for technical assistance. Use of trade names in this paper does not constitute endorsement by the USDA Forest Service.

\section{REFERENCES}

Anderson, J. B., Korhonen, K. \& Ullrich, R. C. (1980) Relationships between European and North American biological species of Armillaria mellea. Experimental Mycology 4: 87-95.

Anderson, J. B. \& Stasovski, E. (1992) Molecular phylogeny of Northern Hemisphere species of Armillaria. Mycologia 84: 506-516.

Anderson, J. B. \& Ullrich, R. C. (1979) Biological species of Armillaria mellea in North America. Mycologia 71: 402-414.

Anderson, J. B. \& Ullrich, R. C. (1982) Diploids of Armillaria mellea: synthesis, stability, and mating behavior. Canadian Journal of Botany 60: 432-439.

Banik, M. T. \& Burdsall, H. H., jr. (1998) Assessment of compatibility in vitro among Armillaria cepistipes, A. sinapina, and North American biological species $X$ and $X I$, using culture morphology and molecular biology. Mycologia 90: 798-805.

Banik, M. T., Volk, T. J. \& Burdsall, H. H., jr. (1996) Armillaria species of the Olympic Peninsula of Washington state, including confirmation of North American biological species XI. Mycologia 88: 492-496.

Bianciotto, V., Barbiero, G. \& Bonfante, P. (1995) Analysis of the cell cycle in an arbuscular mycorrhizal fungus by flow cytometry and bromodeoxyuridine labelling. Protoplasma 188: 161-169.

Bérubé, J. A., Dessureault, M., Berthelay, S. \& Guillaumin, J. J. (1996) Interfertility between Armillaria cepistipes and A. sinapina. Phytoprotection 77: 67-74.

Darmono, T. W. \& Burdsall, H. H., jr. (1992) Morphological characteristics of incompatibility reactions and evidence for nuclear migration in Armillaria mellea. Mycologia 84 : 367-375.

Duchesne, L. C. \& Anderson, J. B. (1990) Location and direction of transcription of the 5S rRNA gene in Armillaria. Mycological Research 94 : 266-269.

Franklin, A. L., Filion, W. G. \& Anderson, J. B. (1983) Determination of nuclear DNA content in fungi using mithramycin; vegetative diploidy in Armillaria mellea confirmed. Canadian Journal of Microbiology 29: 11791183.

Galbraith, D. W., Harkins, K. R., Maddox, J. M., Ayres, N. M., Sharma, D. P. \& Firoozabady, E. (1983) Rapid flow cytometric analysis of the cell cycle in intact plant tissues. Science 220: 1049-1051.

Harrington, T. C. \& Wingfield, B. D. (1995) A PCR-based identification method for species of Armillaria. Mycologia 87: 280-288.

Kim M.-S., Klopfenstein, N. B., McDonald, G. I., Arumuganathan, K. \& Vidaver, A. K. (2000) Characterization of North American Armillaria species by nuclear DNA content and RFLP analysis. Mycologia 92 874-883.

Korhonen, K. (1978) Interfertility and clonal size in the Armillaria mellea complex. Karstenia 18: 31-42.

Korhonen, K. (1980) The origin of clamped and clampless basidia in Armillaria ostoyae. Karstenia 20: 23-27.

Korhonen, K. \& Hintikka, V. (1974) Cytological evidence for somatic diploidization in dikaryotic cells of Armillaria mellea. Archives of Microbiology 95 : 187-192.

Larsen, M. J., Banik, M. T. \& Burdsall, H. H., jr (1992) Clamp connections in North American Armillaria species: occurrence and potential application for delimiting species. Mycologia 84: 214-218.

McDonald, G. I., Larsen, M. J., Klopfenstein, N. B. \& Kim, M.-S. (1998) Mating Armillaria cepistipes and North American Biological Species (NABS) X. Phytopathology 88: S60 [Abstract].

Ormerod, M. G. (1990) Analysis of DNA. In Flow cytometry: A practical approach (M. G. Ormerod, ed.): 69-112. Oxford University Press, New York.

Peabody, D. C., Motta, J. J. \& Therrien, C. D. (1978) Cytophotometric evidence for heteroploidy in the life cycle of Armillaria mellea. Mycologia 70: $487-498$

Tommerup, I. C. \& Broadbent, D. (1975) Nuclear fusion, meiosis and the origin of dikaryotic hyphae in Armillaria mellea. Archives of Microbiology 103: 279-282. 
Ullrich, R. C. \& Anderson, J. B. (1978) Sex and diploidy in Armillaria mellea. Experimental Mycology 2: 119-129.

Veldman, G. M., Klootwijk, J., de Regt, V. C. H. F. \& Rudi, R. J. (1981) The primary and secondary structure of yeast $26 \mathrm{~S}$ rRNA. Nucleic Acids Research 9: 6935-6952.
White, E. E., Dubetz, C. P., Cruickshank, M. G. \& Morrison, D. J. (1998) DNA diagnostic for Armillaria species in British Columbia: within and between species variation in the IGS-1 and IGS-2 regions. Mycologia 90: 125-131.

Corresponding Editor: N. J. Talbot 